\title{
Selection of Parameters for Blade-to-blade Finite-volume Mesh for CFD Simulation of Axial Turbines
}

\author{
Grigorii Popov, Valery Matveev, Oleg Baturin, Yulia Novikova, Andrey Volkov \\ Samara National Research University, Department of Aircraft Engines Theory, 34, Moskovskoye shosse, Samara, 443086, Russia
}

\begin{abstract}
This paper describes the first part of the global work done by the authors aimed at finding the best settings for a numerical model for the calculations of axial uncooled turbines using RANS approach. The authors studied more than 80 papers published over the past 5 years in the examined field. Their analysis did not allow to identify unified recommendations for the creation of numerical models. The selection of model parameters is usually motivated by general considerations of numerical simulation, which follow from the method. In none of the papers the selection of parameters is correlated with the structure of the flow in the turbine. Many specific simulation issues were not covered at all.

For the research, more than 1000 models of full-size axial turbines (including multistage turbines) and their elements were created. They differed in the number, size, parameters of the elements of finite volume meshes, in turbulence models, in the degree of simplification. The results were compared with the experimental data.

As a result, the following was obtained:

1. A method for developing and optimizing the working process of turbines using numerical simulation based on the RANS approach is proposed. The search for the optimal turbine configuration is carried out using light computational models, which are based on the simplified channel geometry and the finite volume mesh. Their application makes it possible to reliably find the optimal turbine configuration 2.8 times faster. The characteristics of the selected variants are verified with the help of verification models that consider the real geometry of the channels and have a minimum error.

2. Recommendations are given on the selection of parameters for finite volume meshes and the selection of turbulence models for numerical models of the working process of axial turbines designed to perform optimization and verification calculations.
\end{abstract}

\section{Nomenclature}

GTU - gas turbine unit

GTE - gas turbine engine

LPT - Low pressure turbine

FT - free turbine

$\mathrm{y}+-$ dimensionless distance

RANS - Reynolds-averaged Navier-Stokes equations

$E R_{F P}=\frac{y_{F P i}}{y_{F P i-1}}-$ cell expansion ratio of the finite volume mesh

$M R_{F P}=\frac{y_{F P \max }}{y_{F P 1}}-$ maximum cell aspect ratio of the finite volume mesh

$\mathrm{y}_{\mathrm{FP} 1}$-size of the element of the finite volume mesh closest to the endwall.

$\mathrm{y}_{\mathrm{B} 2 \mathrm{~B} 1}$ - size of the element of the finite volume mesh closest to the blade surface

CIAM - Central Institute of Aviation Motors

$\zeta_{\mathrm{PR}}-$ profile losses

$\lambda$ - specific velocity

$\beta_{1}$ - inlet flow angle of the cascade, degree $\beta_{2}$ - outlet flow angle of the cascade, degree

$\sigma_{\text {res }}^{2}\left(\zeta_{P R}\right)$-residual dispersion

$\mathrm{F}-\mathrm{F}$-ratio test

qMSE - mean square error

$q M S E_{\text {rel }}\left(\zeta_{P R}\right)$ - mean relative square errors

$\zeta_{\mathrm{EXP} \text { mean }}-$ mean experimental value of profile losses

$\mathrm{S}-$ calculation speed up

$\eta_{\mathrm{PR}}$ - cascade efficiency

$\pi_{\mathrm{T}}^{*}$ - gas expansion ration in turbine

$\alpha_{\text {OUT }}-$ outlet flow angle of the turbine, degree

$A_{\mathrm{T}}^{*}$ - throughflow capacity of the turbine, $\mathrm{m}^{3} K^{-0.5} \mathrm{~s}^{-1}$

$\mathrm{n}$ - rotational speed, $\mathrm{rpm}$

$c_{S}^{*}$ - isentropic rate of gas expansion in a turbine, $\mathrm{m} / \mathrm{s}$

$\mathrm{E}$ - efficiency of parallelization of a computational task

B2B - two-dimensional blade passage

$\mathrm{FV}$ - finite volumes.

\section{Introduction}

The world market of mainline aircraft engines until 2033 is estimated at 7400 pieces with a total cost of $\$ 1028$ billion [1]. Until 2024, the delivery of 13000 industrial 
gas turbines is expected. Thus, gas turbine engine building is a dynamically developing and financially attractive segment of the world economy [1].

The competitiveness of the engines is largely determined by their fuel efficiency. At the same time, it essentially depends on the gas dynamic efficiency of lowpressure turbines, as well as free turbines. The effect of their efficiency on the specific fuel consumption can be estimated as follows: $1 \%$ increase in LPT efficiency reduces fuel consumption of turbofan engine by approximately $0.7 \%$, and $1 \%$ increase in FT efficiency reduces fuel consumption of GTU engine by about $1 \%$ [2]. For this reason, axial uncooled turbines of aircraft and industrial gas turbine engines with aerodynamically long blades were chosen as the object of research.

At present, the methods of computational gas dynamics are widely used in the design and development of turbines [3]. Their use, although it is associated with a significant expenditure of time and computing resources, however, makes it possible to determine the characteristics of turbines without experiment with high reliability (with respect to other calculation methods) [4]. In addition, the application of numerical simulation makes it possible to widely use methods of mathematical optimization during the development of turbines [5]. Due to the complexity of the configuration of the blades and other elements of the turbine flow part, their optimization is associated with the variation of many parameters. This inevitably leads to an increase in the time of obtaining the final optimization result: the solution of the applied problem of turbine optimization may require about 3000 iterations with the mathematical model [5].

At present, there is a need to obtain efficient 3D numerical models of the working process of uncooled axial turbines for their use in optimization and development. Here and below, effective 3D models are numerical computational models that combine the maximum simulation accuracy with the shortest calculation time.

The authors analyzed more than 80 publications в issued in ASME conference proceedings over the past 5 years, which described the results of studies related to the numerical simulation and optimization of the working process of axial turbines (Appendix A). It showed that, despite the extensive use of numerical simulation, there is no consensus on what criteria should be used to describe the mathematical models and what quantitative settings should be used to obtain the best simulation efficiency.

In addition, there are not enough estimates of the influence of the most important parameters of the numerical models of the turbine working process, not only on the accuracy of simulation, but also on the time and computing resources required for the solution. The authors also failed to find recommendations for the selection parameters of the numerical models of uncooled axial turbines intended specifically for performing optimization or verification calculations based on simulation efficiency, considering both the calculation error and the calculation speed of numerical models.

Thus, the goal of this work was the development of specific recommendations for the creation of numerical models of the working process of axial uncooled turbines with aerodynamically long blades for carrying out optimization and verification calculations that combine greater accuracy in predicting parameters and require moderate computing resources.

The efficiency of numerical simulation is influenced by many different factors, such as used physical models, discretization algorithms, methods of solving the system of equations, the size and topologies of the finite volume mesh, the turbulence models and others [6]. In this paper, only recommendations on the selection of the finite volume mesh parameters and turbulence model will be sought, i.e. those parameters that the engineer can influence in real project practice.

The mesh parameters and turbulence model affect both the accuracy of the simulation and the calculation speed. Parameters of parallelization of model calculations by computational kernels also have a significant effect on the simulation speed.

\section{Analysis of recommendations in the technical literature on the construction of numerical models of uncooled axial turbines}

At the first stage of the work, the process of numerical simulation of viscous compressible gas flow was analyzed based on the solution of time-averaged NavierStokes equations (RANS) [7,6]. Two basic requirements are imposed on the numerical models of the working process of axial turbines used in the design and optimization. On the one hand, they must accurately describe the working processes occurring in the turbine. On the other hand, they should require a short time to get a solution.

Analysis of 80 publications issued in ASME conference proceedings over the last 5 years related to the study and optimization of the working process of axial turbines showed that among all the parameters that are adjusted in the creation of numerical models, the authors pay the greatest attention to the parameters of the finite volume mesh and to the selected turbulence models that is not surprising, since these are the parameters, the selection of which is available to a typical engineer.

The results of the analysis of publications are summarized in the form of histograms in Fig. 1...4.

As a result of the analysis, unified universal recommendations on the creation of numerical models of the working processes of axial turbines have not been revealed. The researchers do not have a shared vision on what parameters should describe the configuration of the mesh, different authors use different combinations of parameters. If there are some recommendations on the selection of the number and size of the finite volumes in the two-dimensional blade passage, recommendations for selecting the parameters determining the distribution of the elements along the height of the flow part of turbines with different blade heights are absent.

It is interesting to note that only 70 of the almost 80 reviewed studies contain at least a minimal description of the numerical models and the laws governing the selection of their parameters. It is also interesting to note 
that only 18 papers study the effect of model parameters on the accuracy of calculations. Analysis of the effect of the settings on the calculation speed was not found.

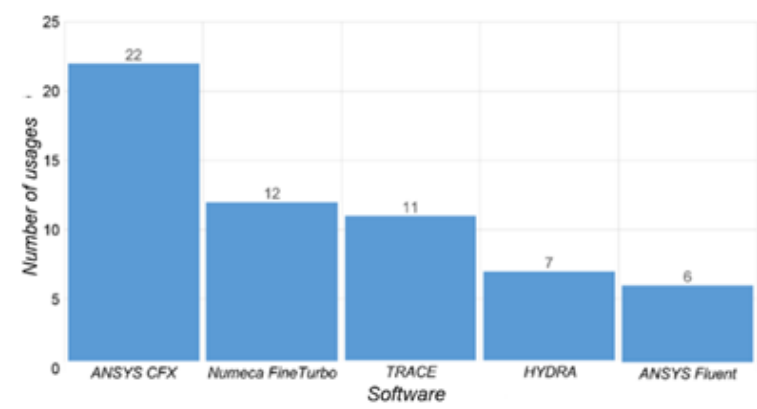

Figure 1. The use of commercial software in numerical simulation of turbine working process.

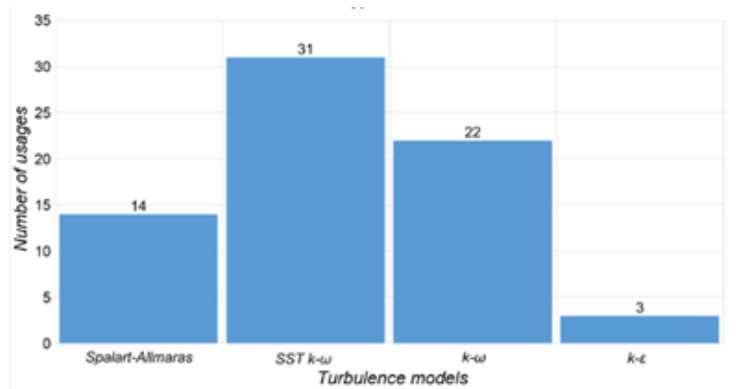

Figure 2. The use of turbulence models in numerical simulation of turbine working process.

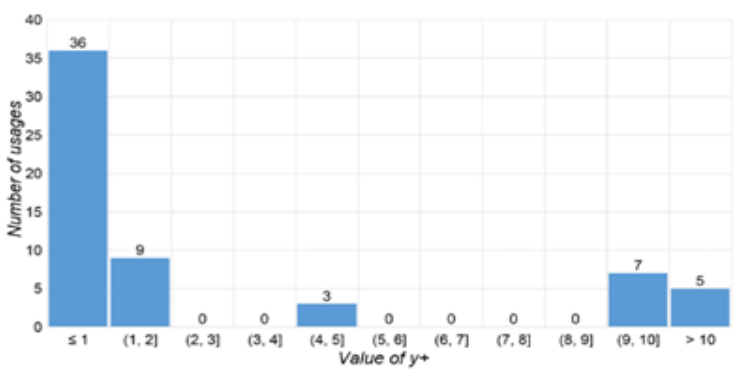

Figure 3. Selection of the parameter $y_{1}^{+}$of computational meshes.

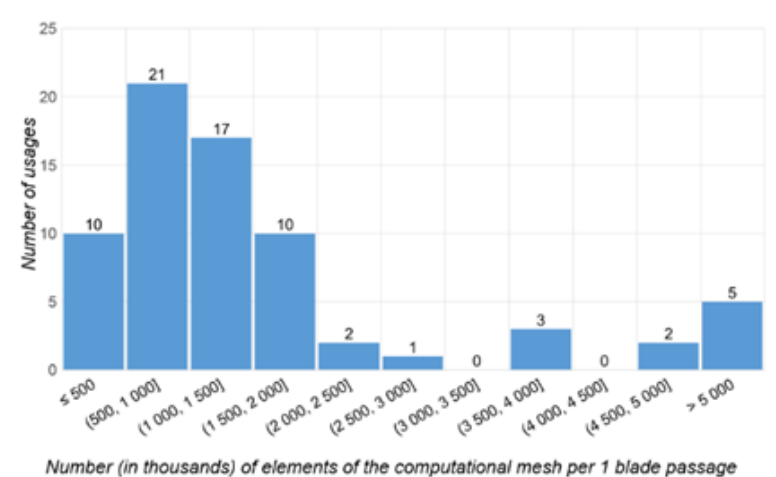

Figure 4. The selection of the number of finite volumes in one blade passage.

When analyzing the ASME sources, attention was drawn to the fact that the selection of the parameters of numerical models is usually motivated by general considerations of numerical simulation, which follow from the method itself. None of the papers correlate the selection of parameters with the flow structure in the investigated turbine passage, which, in the authors' opinion, is a serious drawback of all the studies.

Nevertheless, according to the survey of the results of turbine workflow studies and the literature describing the basics of CFD simulation [6], the most frequently encountered (generally accepted) recommendations for selecting the parameters of numerical models of the turbine workflow were defined:

- number of elements in a 3D mesh of one blade row: from 0.5 million to 1.5 million;

- number of elements in the 2D mesh of the blade row: from 10,000 to 20,000 ;

- value of the dimensionless parameter $y+$ on the surfaces of the endwalls and blades: $y+=1$;

- turbulence model: k- $\omega$, SST or Spalart-Allmaras;

- value of cell expansion ratio (Expansion Ratio) up to 1.4 .

\section{Analysis of the flow structure in the blade row of the axial turbine}

At the next stage, the structure of the flow of the working fluid in the blade passages of axial turbines was analyzed $[1,3]$. There two characteristic zones can be distinguished: the main flow (the core of the flow) and the secondary flow (around the endwalls) (Fig. 5).

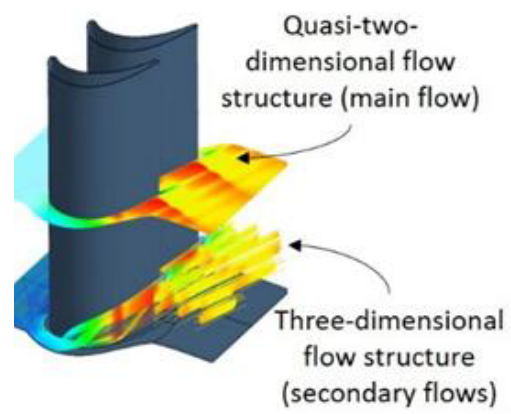

Figure 5. Flow structure in the blade row of the axial turbine.

In the main region, the flow is quasi two-dimensional, so the main parameters of the $2 \mathrm{D}$ mesh affect the flow simulation in this region: the $y_{B 2 B 1}^{+}$parameter, characterizing the size of the element closest to the blade surface, and the number of elements along the sides of topological blocks $n_{i}$ that determine the total number of elements of the 2D mesh B2B (Fig. 6).

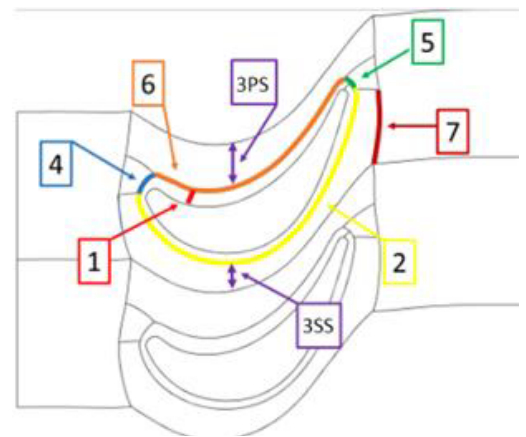

Figure 6. Topological blocks of B2B finite volume mesh of blade passage. 
In the secondary region, the flow pattern is threedimensional and develops along the streamlines and along the height of the flow part (Fig. 5). Therefore, the simulation of the flow structure in this region is influenced not only by the parameters of the 2D mesh, but also by the parameters of the distribution of the elements along the height of the flow part. To characterize the distribution of elements along the height of the flow part, it is suggested to use the size of the element closest to the endwalls $\mathrm{y}_{\mathrm{FP} 1}$, the cell expansion ratio $E_{\mathrm{FP}}$ and the maximum cell aspect ratio $\mathrm{MR}_{\mathrm{FP}}$, which are calculated as: $E R_{F P}=\frac{y_{F P i}}{y_{F P i-1}}, M R_{F P}=\frac{y_{F P \max }}{y_{F P 1}}$ (Fig. 7). Under the condition $\mathrm{y}_{\mathrm{FP} 1}=\mathrm{y}_{\mathrm{B} 2 \mathrm{~B} 1}$, as a rule, the equality of $y_{F P 1}^{+}=y_{B 2 B 1}^{+}$is provided, and the distribution of the elements along the height of the flow part is determined by only two parameters: $\mathrm{ER}_{\mathrm{FP}}$ and $\mathrm{MR}_{\mathrm{FP}}$.

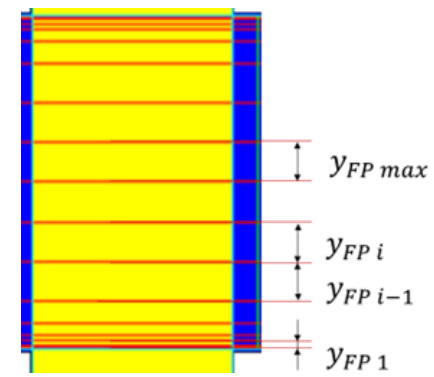

Figure 7. Distribution of finite volumes over blade height in the computational model of an axial turbine [8].

The complex nature of the flow pattern in the blade passages of the axial turbine leads to the fact that the energy losses along the height of the flow part vary unevenly (Fig. 8). Profile losses occur along the entire height of the blade, determining the overall level of losses and some integral parameters of the turbines. Therefore, the selection of the values of the parameters of $2 \mathrm{D}$ mesh should be carried out according to the profile losses determined during the simulation for individual rows or by integral parameters of turbines. Secondary losses have a complex distribution over the height of the blade and act only near the end surfaces of the flow part. Therefore, when selecting the values of the $\mathrm{ER}_{\mathrm{FP}}$ and $\mathrm{MR}_{\mathrm{FP}}$ parameters, it is necessary to evaluate the distribution of the flow parameter values (for example, loss coefficients, flow angle, total pressure) along the height of the flow part.

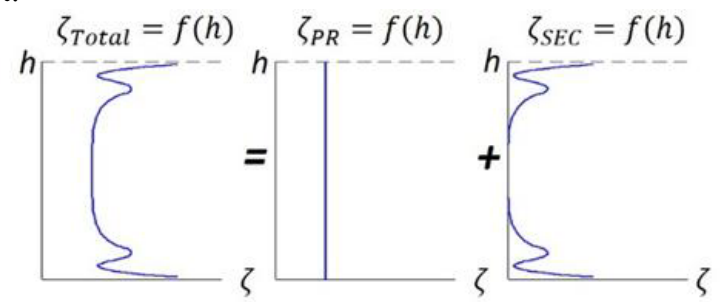

Figure 8. Typical distribution of losses along the blade height.

Based on the above, it was suggested to find recommendations on the construction of a finite volume mesh during the study and optimization of the working process of axial air turbines, relying not only on the fundamental principles of numerical simulation, but also on the features of the flow of the working fluid in these channels. The study is supposed to be conducted in 2 stages. At the first stage, the influence of the mesh parameters on the simulation efficiency of the working process of the three gas turbine cascades tested at CIAM [10] will be evaluated for the six turbulence models most frequently used in the investigations of the researchers. At the second stage, a check of recommendations developed at the first stage during the simulation of the workflow of ten full-size turbines of aviation and ground GTE will be performed. The research was carried out in the software Numeca and Ansus CFX, as the most widely used at the enterprises of the engine building industry in Russia.

\section{Investigation of the influence of parameters of finite volume mesh and turbulence models on the simulation efficiency of the working process of gas turbine cascades}

A study on the effect of the parameters of finite volume mesh and turbulence models on the simulation efficiency of the working process of gas turbine cascades was carried out basing on the data from the atlas [10]. It was created at the Central Institute of Aviation Motors (Russia). The atlas contains the results of the experimental determination of profile losses in more than 170 untwisted axial turbine cascades of a constant crosssectional height. These data were obtained at various enterprises of the former USSR and summarized in CIAM.

Experimental studies of cascades were carried out using a special automated test rig, schematically depicted in Fig. 9. The test rig operated in the exhauster mode: at the cascade inlet the pressure and flow temperature were close to atmospheric, the level of turbulent pulsations did not exceed $\varepsilon_{1}=0.02 \ldots 0.05$. . When the reduced flow velocity behind the cascade was changed within the range of $\varepsilon_{1}=0.02 \ldots 0.05$ and the profile chord was changed in the range of $\mathrm{b}=50 \ldots 80 \mathrm{~mm}$, the Reynolds number was in the range $R e=(0,6 \ldots 1,0) \cdot 10^{6}$. The air total temperature at the inlet to the test rig was $T_{\text {air } 0}^{*} \approx 295 \mathrm{~K}$ [10].

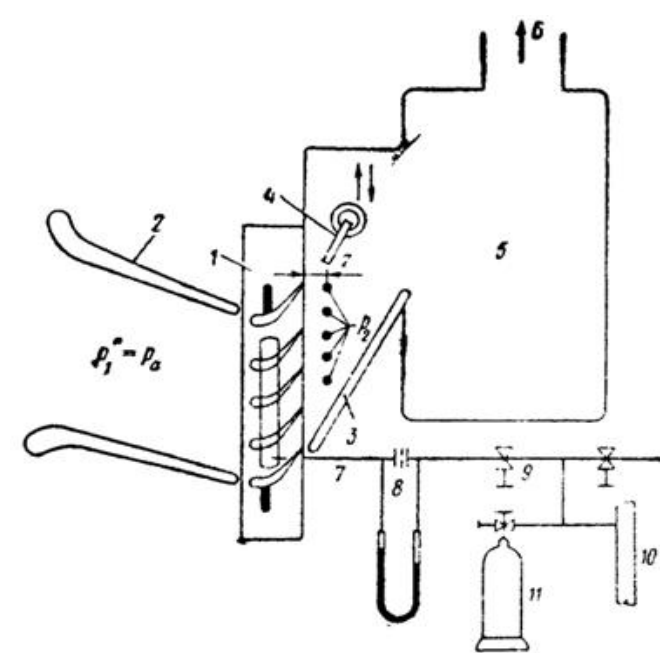

Figure 9. Scheme of the test rig for blowdowns of cascades. 
The experimental cascades were assembled from $8 . . .9$ blades of constant cross section with a height of $125 \mathrm{~mm}$. To cut off and drain the boundary layer formed on the walls of the rig prior to cascade inlet, cut-off plates were installed on the blades at a distance of 5-40 $\mathrm{mm}$ from the end surfaces of the blade passage. The actual height of the blades between the cutoff plates was $\mathrm{h}=30 \ldots 100 \mathrm{~mm}$.

During the tests, the fields of total and static pressures behind the cascades were measured at a distance of $\mathrm{Z}=(0.3 \ldots 1.5) \mathrm{a} \_2$ from the trailing edges (a_ 2 is the throat of the blade row). The static pressure was measured by pressure extraction through the holes located on the cutoff plate in the amount of $20 \ldots 35$ pieces, and also in the flow by means of a special combined probe (Fig. 10).

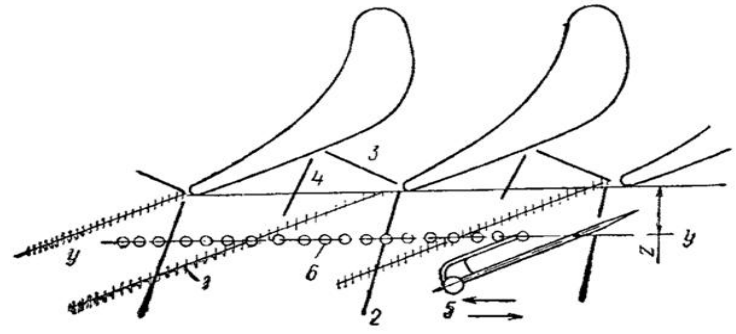

Figure 10. Flow structure behind the transonic cascade and probe for measuring flow parameters.

Three cascades typical for LPT and FT were selected for the research. They differed from each other by the values of the blade angles at the inlet and outlet $\beta_{1 \mathrm{~b}}$ and $\beta_{2 \mathrm{~b}}$. Experimentally determined characteristics are known for all cascades. That are the dependencies of profile losses from specific isentropic velocity at the outlet $\zeta_{\mathrm{pr}}=\mathrm{f}\left(\lambda_{2 \mathrm{~S}}\right)$ (for the cascade No. 168 [10] at two values of inlet flow angle $\beta_{1}$ ). Characteristics in the form of the dependence of the outlet flow angle of the cascade from specific isentropic velocity at the outlet $\beta_{2}=\mathrm{f}\left(\lambda_{2 \mathrm{~S}}\right)$ were known for the cascade No. 1 [10]. In addition, experimentally determined loss distributions over the blade height $\zeta=\mathrm{f}(\mathrm{h})$ were known for all the cascades.

At the first stage, the workflow for all selected cascades was calculated using numerical models based on recommendations found in the literature sources: the number of elements in 2D mesh was about 14000, the $y_{B 2 B 1}^{+}$parameter was 1 , the $\mathrm{ER}_{\mathrm{FP}}$ and $\mathrm{MR}_{\mathrm{FP}}$ parameters were 1.4 and 1000 , respectively. These numerical models are hereinafter referred as basic models. The number of elements in the basic three-dimensional meshes for all cascades was about 1.1 million. The procedure for processing the results of the calculation was completely consistent with the procedure for processing the experimental data [10].

For the obtained in the calculation results, an estimation of their adequacy to the experimental data using the residual dispersion $\sigma_{\text {res }}^{2}\left(\zeta_{P R}\right)(1)$ and the Fratio test $F$ (2) was made. The absolute error was characterized by mean square error qMSE (3). The relative errors in determining the profile loss coefficient $\zeta_{\mathrm{pr}}$ and the efficiency of the cascade $\eta_{\mathrm{PR}}$ were characterized by the mean relative square errors $q M S E_{r e l}\left(\zeta_{P R}\right)(4)$ and $q M S E_{r e l}\left(\eta_{\mathrm{PR}}\right)(5)[11]$ :

$$
\begin{gathered}
\sigma_{\mathrm{res}}^{2}\left(\zeta_{P R}\right)=\operatorname{MSE}\left(\zeta_{P R}\right)=\frac{1}{n-m} \sum_{i=1}^{n}\left(\zeta_{\mathrm{EXP} i}-\zeta_{\mathrm{PR} i}\right)^{2} ;(1) \\
F=\frac{\sigma_{\mathrm{res}}^{2}}{\sigma_{y}^{2}} ; \\
q M S E\left(\zeta_{P R}\right)=\sqrt{M S E\left(\zeta_{P R}\right)} ; \\
q M S E_{\text {rel }}\left(\zeta_{P R}\right)=\frac{q M S E\left(\zeta_{P R}\right)}{\zeta_{E X P \text { mean }}} \cdot 100 \% ; \\
q M S E_{\text {rel }}\left(\eta_{P R}\right)=\frac{q M S E\left(\zeta_{P R}\right)}{1-\zeta_{\text {EXP mean }}} \cdot 100 \%,
\end{gathered}
$$

The estimation of the calculation speed was carried out using the speed up parameter $\mathrm{S}$, which was defined as the ratio of the calculation time of one iteration $t_{B A S I C, S A}$ of the basic numerical model and the SpalartAllmaras turbulence model to the time of calculation of one iteration $t_{\text {Mesh } i, \text { Turb } j}$ of the numerical model with i-th mesh and j-th turbulence model: $S=$ $t_{B A S I C, S A} / t_{\text {Mesh } i, \text { Turb } j}$.

The results of calculation of the cascade characteristics using the basic computational meshes and six turbulence models showed that all 24 calculation characteristics (4 turbine cascades using 6 turbulence models) in the form of $\zeta_{P R}=f\left(\lambda_{2 S}\right)$ are adequate to experimental data. Fig. 11 shows an example of the results obtained for the cascade No. 1 [10]. The smallest errors in determining the coefficients of the profile losses $\zeta_{P R}$ and the efficiency of cascade $\eta_{P R}$ are achieved using k- $\omega$ (Wilcox) and SST turbulence models. All the calculation characteristics of the type $\beta_{2 \text { mean }}=$ $f\left(\lambda_{2 S}\right)$ are also adequate to the experimental ones, and the absolute errors in the determination of $\beta_{2 \mathrm{cp}}$ using different turbulence models are approximately the same and is about $1^{\circ}$. At the same time, none of the numerical models makes it possible to adequately predict the distribution of secondary losses along the height of the flow part $\zeta_{S E C}=f(h)$.

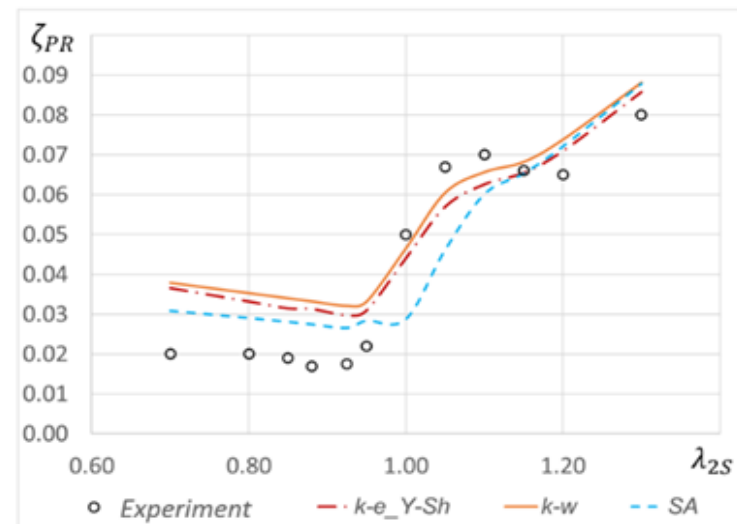

Figure 11. Comparison of the experimental and calculated characteristics $\zeta_{P R}=f\left(\lambda_{2 S}\right)$ obtained with basic meshes and various turbulence models on the example of cascade No. 1 [10]

The next step was to assess the effect of the number of 2D B2B mesh elements on simulation efficiency. In 
the framework of the research based on the basic meshes, 4 additional meshes were created for each cascade in which the number of 2D B2B mesh elements varied from 6000 to 34000 . When creating meshes, the number of elements along the sides of the topological blocks of twodimensional mesh was changed according to the expression $n_{B 2 B i} \approx n_{B 2 B 0} \cdot 1.25^{i}$ where $n_{B 2 B 0}$ is the number of elements along some topological block in the basic mesh; $n_{B 2 B i}$ is the number of elements along the same topological block in B2Bi mesh ( $\mathrm{i}=-2,-1,0,1$, $2)$. Each of the meshes was calculated using 6 turbulence models. In total, 120 calculation characteristics in the form of $\zeta_{P R}=f\left(\lambda_{2 S}\right)$ were obtained, 116 of which turned out to be adequate to experimental data. The change in the number of elements and the turbulence model does not change the behavior of the calculation characteristics $\zeta_{P R}=f\left(\lambda_{2 S}\right)$, but leads only to a certain shift along the ordinate axis (Fig. 12). With an increase in the number of elements of two-dimensional mesh of more than 21,000 (corresponding to the B2B1 mesh), their effect on the level of estimated losses becomes extremely small (Fig. 13). The change in the number of elements of twodimensional mesh has practically no effect on the characteristics $\beta_{2 \text { mean }}=f\left(\lambda_{2 S}\right)$.

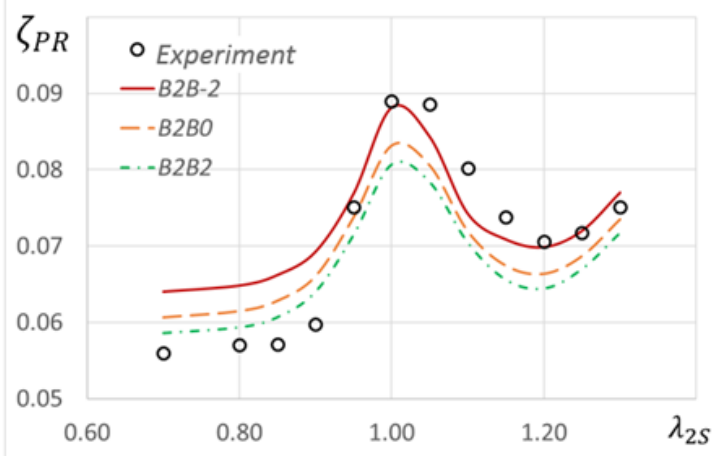

Figure 12. Comparison of the experimental and calculated characteristics obtained with different number of 2D mesh elements (on the example of cascade No. 34 [10]).

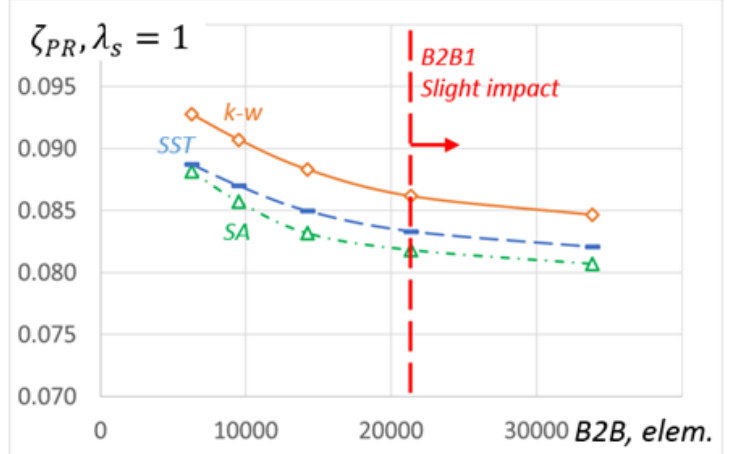

Figure 13. Influence of the number of 2D mesh elements on calculated values of the profile loss coefficients (on the example of cascade No. 34 [10]).

The absolute and relative errors in determining the profile losses and the efficiency of the turbine cascade do not significantly depend on the number of elements of two-dimensional mesh (Fig. 14). In this case, the speed up of the calculation $\mathrm{S}$ increases by 2 times with a decrease in the number of elements of two-dimensional mesh to 6000 (Fig. 15). An increase in the number of elements of two-dimensional mesh leads only to a local refinement of the simulated flow structure. Thus, it is advisable to use B2B-2 meshes $(6000$ elem. $)$ for optimization calculations, and B2B1 (21000 elem.) meshes for verification ones.

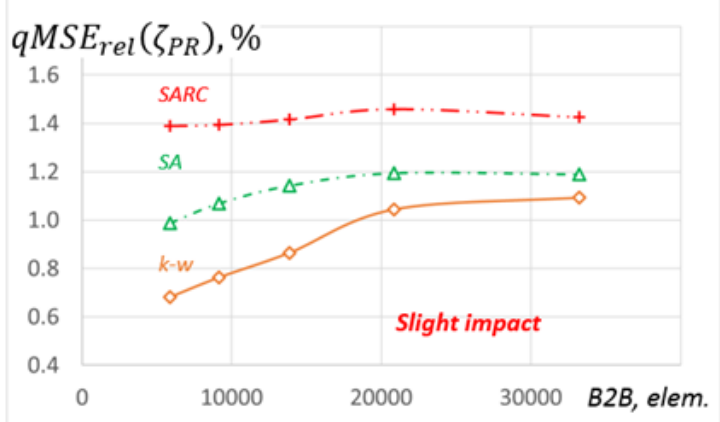

Figure 14. Influence of the number of 2D mesh elements on the relative error of the calculation $q M S E_{r e l}\left(\zeta_{P R}\right)$ (on the example of cascade No. $\left.168, \beta_{1}=30^{\circ}[10]\right)$.

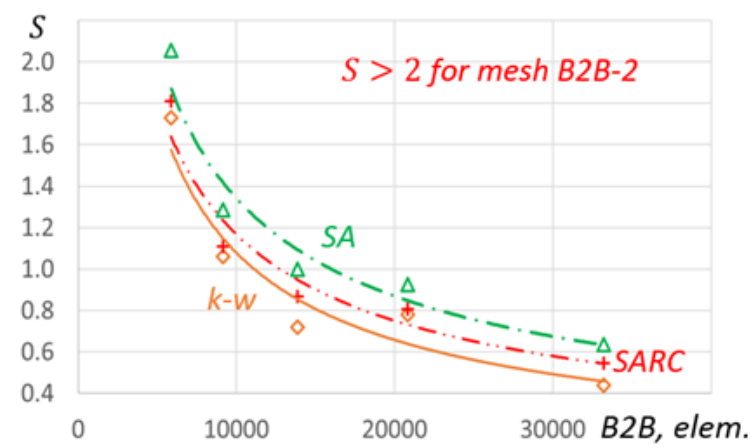

Figure 15. Influence of the number of $2 \mathrm{D}$ mesh elements on the calculation speed up $\mathrm{S}$ (on the example of cascade No. 168, $\left.\beta_{1}=30^{0}[10]\right)$.

Then, the effect of the $y_{B 2 B 1}^{+}$parameter on the simulation efficiency was studied. In the framework of the research based on the basic meshes, 4 additional meshes were created differing only in the value of the $y_{B 2 B 1}^{+}$parameter, which varied from 0.2 to 5.0. Each of the meshes was calculated using 6 turbulence models (in total, 120 numerical models). It turned out that a significant part of the calculation characteristics $\zeta_{P R}=$ $f\left(\lambda_{2 S}\right)$ obtained for the values of the $y_{B 2 B 1}^{+}$parameter greater than 2 is not adequate to the experimental data.

The change in the $y_{B 2 B 1}^{+}$does not affect the behavior of the obtained characteristics $\zeta_{P R}=f\left(\lambda_{2 S}\right)$ and only shifts them along the ordinate axis. As the $y_{B 2 B 1}^{+}$ parameter decreases below 1 , its effect on the level of calculated profile losses becomes insignificant. The change in the $y_{B 2 B 1}^{+}$parameter has practically no effect on the characteristics $\beta_{2 \text { mean }}=f\left(\lambda_{2 S}\right)$. Absolute and relative errors in the determination of profile losses and efficiency are also practically constant at $y_{B 2 B 1}^{+}$less than 1 and increase substantially for $y_{B 2 B 1}^{+}$values greater than 1 (Fig. 16). The parameter $y_{B 2 B 1}^{+}$does not influence 
the calculation speed up S, as well as the calculated flow structure. Thus, for simulation it is necessary to use meshes in which $y_{B 2 B 1}^{+}=1$.

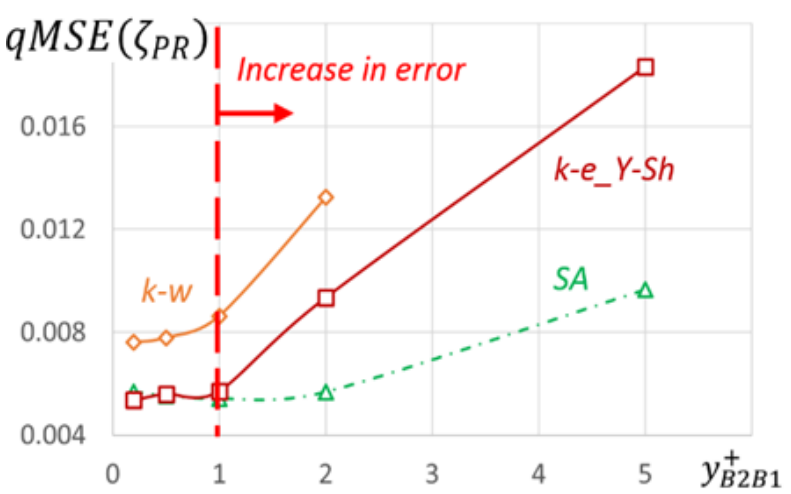

Figure 16. Influence of the $y_{B 2 B 1}^{+}$parameter on the absolute error $q M S E\left(\zeta_{P R}\right)$ (on the example of cascade No. 34 [10]).

\section{Conclusion}

Recommendations for conducting studies on the selection of mesh parameters have been developed based on the concept of the flow structure in the blade passages of turbines with aerodynamically long blades, according to which the selection of the 2D mesh parameters is necessary to perform based on the calculated profile losses for individual rows or by integral parameters of turbines. The selection of the parameter values $E R_{F P}$ and $M R_{F P}$ must be performed based on the distribution of flow parameters along the height of the flow section.

The recommendations on the selection of parameter values of $\mathrm{B} 2 \mathrm{~B}$ mesh for numerical models of the working process of the turbine cascades, designed to perform optimization calculations, have been developed. For optimization calculations, it is advisable to use numerical models in which two-dimensional B2B-2 meshes are used (about 6000 elements), The value of the parameter $y_{1}^{+}+$is 1 .

The recommendations on the selection of parameter values of B2B mesh for numerical models of the working process of the turbine cascades with aerodynamically long blades, designed to perform verification calculations have been developed. For verification calculations, it is advisable to use two-dimensional meshes B2B1 (about 21000 elements).

The next stage of the work is devoted to the selection of parameters 3D finite-volume mesh for CFD simulation of axial turbines are described in [12].

\section{Acknowledgments}

This work was supported by the Ministry of Education and scenes of the Russian Federation in the framework of implementation of the Program of increasing the competitiveness of Samara University among the world's leading and educational centers for 2013-2020 years.

\section{Appendix A}

\begin{tabular}{|c|c|}
\hline $\begin{array}{c}\text { Release year } \\
\text { of the proceedings } \\
\text { ASME Turbo Expo }\end{array}$ & Article numbers \\
\hline & $45166,45167,45188,45192$, \\
& $45222,45250,45342,45557$, \\
& $45578,45647,45728,45798$, \\
GT2011 & $45931,46113,46204,46221$, \\
& $46309,46511,46718,46729$, \\
& 46757,45909 \\
\hline & $68261,68501,68569,68981$, \\
GT2012 & $68983,69089,69173,69228$, \\
& $69306,69435,69553,69838$ \\
\hline GT2013 & $94055,94109,94141,94509$, \\
& $94686,94872,95148,95314$, \\
& $95433,95628,95670,95843$ \\
\hline GT2014 & $25185,25458,25501,25599$, \\
& $25630,25868,26190,26215$, \\
& $26320,26335,26571,26587$, \\
& $26628,26784,26832$ \\
\hline GT2016 & $42226,42237,42426,42514$, \\
& $42696,42920,42970,43062$, \\
& $43118,43173,43235,43349$, \\
& $463395,43721,43871$ \\
\hline GT2015 & \\
\hline &
\end{tabular}

\section{References}

1. A.A. Inozemcev, I. Lee, J.R. Baker jr., M.M. Banaszak Holl, B.G. Orr, Eur. Phys. J. E 14, 7 Development of a line of civil gas turbine engines (Razvitie linejki grazhdanskih GTD), Report, CIAM (2015)

2. G. Wilfert, S. Joerg, A. Rolt, N. Baker, and A. Touyeras, New Environmental Friendly Aero Engine Core Concepts, Proceedings of the ISABE 2007, Paper 1120 (2007)

3. H. Moustapha, M. F. Zelesky, N. C. Baines, and D. Japikse, Axial and Radial Turbines, Concept NREC (2003)

4. D.D. Corriveau, and S.A. Sjolander, Experimental and Numerical Investigation on the Performance of a Family of Three HP Transonic Turbine Blades, Proceedings of ASME Turbo Expo, pp. 1015-1026 (2004)

5. V.N. Matveev, G.M. Popov, O.V. Baturin, E.S. Goryachkin, and D.A. Kolmakova, Workflow optimization of multistage axial turbine, Proceedings of 51st AIAA/SAE/ASEE Joint Propulsion Conference AIAA Propulsion and Energy Forum, AIAA 2015-4129 (2015)

6. D.V. Nikushhenko, Investigation of viscous noncompressible fluid flows based on the FLUENT computation complex (Issledovanie techenij vjazkoj nezzhimaemoj zhidkosti na osnove raschjotnogo kompleksa FLUENT), Izd. SPbGMTU (2004)

7. J. D. Jr. Anderson, Computational Fluid Dynamics, McGraw-Hill Education (1995)

8. NUMECA, User Manual AutoGrid5 Release 8.4, NUMECA.inc. (2008)

9. W.J. Whitney, F.P. Bebning, T.P. Moffit, G.M. Hotz, Cold-air investigation of $4 \frac{1}{2}$ stage turbine with a 
stage loading factor of 4.66 and high specific work output. I - Overall Performance, NASA TM X-3498 (1977)

10. V.D. Venediktov, and A.V. Granovsky, The Atlas of Experimental Performances of Cooled Gas Turbine Blade Cascades (Atlas eksperimental'nykh kharakteristik ploskikh reshetok okhlazhdaemykh gazovykh turbin), CIAM (1990)
11. B.R. Frieden, Probability, Statistical Optics, and Data Testing. Springer, 508 p. (2001)

12. G. Popov, V. Matveev, O. Baturin, J. Novikova, D. Kolmakova, A. Volkov, Selection of parameters for 3D finite-volume mesh for CFD simulation of axial turbines (to be published) 